\title{
A Study of Conceptual Metaphors in The Bluest Eye
}

\author{
GE Ruizhen, GAO Wencheng \\ University of Shanghai for Science and Technology, Shanghai, China
}

\begin{abstract}
The Bluest Eye is seldom studied from a linguistic perspective. Conceptual metaphor is the latest achievement in cognitive linguistics. Metaphor is a kind way of thinking and action. The research question is: What conceptual metaphors are embodied in the Bluest Eye? And how these conceptual metaphors reflect the theme of the novel? Four conceptual metaphors are discovered in the novel. The first one is 'LIFE IS FOUR SEASONS'. The cycle of seasons represents birth, growth, death, and regeneration. The second one is 'A BLACK SLAVE IS A BIRD IN A CAGE'. A bird represents freedom, but Pecola is imprisoned by the social environment. 'VALUE IS DOLL' is the third conceptual metaphor. The doll symbolizes beauty; however, Pecola is regarded as an ugly girl, so she has no doll. The fourth one is 'DEATH OF HOPE IS MARIGOLD'. Marigold is often related to death; Pecola's miserable life experience made her life rather than death. Through these four conceptual metaphors, the author conveys the unfairness and racial discrimination of the society at that time. The author appeals to the society to treat everyone equally, including black people.
\end{abstract}

Keywords: The Bluest Eye, conceptual metaphors, black people, racial discrimination

\section{Introduction}

The publication of Metaphors We Live By by Lakoff and Johnson in 1980 is regarded as a milestone in the history of cognitive linguistics. Metaphorical expressions not only lie in language, but also in the process of individual thinking (Lakoff \& Johnson, 1980). Conceptual metaphor includes: structural metaphor, orientational metaphor, and ontological metaphor. Structural metaphor is a mapping from one conceptual structure to another (Lakoff \& Johnson, 1980). After understanding the characteristics of the source domain, we can better interpret and reconstruct the target domain. Structural metaphors come from our experience. As for ontological metaphor, Kovecses (2002) held that people can understand the intangible, abstract, and immaterial experiences into the concrete characteristics of objects or materials through ontological metaphors, so as to enhance our understanding of these abstract concepts. That is to say, the transformation of ontological metaphor is a kind of transformation from the abstract to the concrete. Ontological metaphor: The physical metaphor regards the intangible concept as concrete and tangible, and understands the former through the experience of the physical, while container metaphor refers to the concept of illusory intangibility as a kind of container that allows it to enter and exit, to have a range. And personification: The formation of conceptual metaphor is based on human experience. For example, in English, one can often see mouth of a well, foot of the hill, and so on. It expresses humans self-centered, through observation, understanding, and recognition to

GE Ruizhen, master, College of Foreign Languages, University of Shanghai for Science and Technology, Shanghai, China.

GAO Wencheng, doctor, professor, College of Foreign Languages, University of Shanghai for Science and Technology, Shanghai, China. 
recognize things around. Through their own media, man may have a better understanding of the rapidly changing nature of mystery. Thus, we can know that anthropomorphism is to look at some physical objects as adults, or to look at non-human things as adults. On the basis of these examples, we suggest the following conclusions about the experiential grounding, the coherence, and the systematicity of metaphorical concepts. There is an internal systematicity to each orientational metaphor. For example, "Happy is up" defines a coherent system rather than a number of isolated and randomized cases. They are characterized not by one general tendency but by common events in our life experiences.

The place of this story is Lorraine, USA, in 1941. The protagonist is Claudia who grew up in a black community. Claudia, because she was black, had been talked about by her neighbors. Claudia wants to be like a little white girl with big blue eyes, and in this way, her life will change differently and be loved by the family. But Claudia's wish could not be fulfilled. After she was raped, her life became even more miserable and eventually led to her mental collapse. In practice, however, Claudia could not see life and society accurately. Through this kind of contents construction, the author lets people deeply ponder the social system and the morals. In The Bluest Eye, the author uses conceptual metaphors of dolls, seasons, birds, and flowers to depict the negative influence of racial discrimination and sexism on black people. Through related metaphorical expressions, the author emphasizes the spiritual harm suffered by black people in that period, which leads people to think about social development and rights protection.

\section{Literature Review}

The Bluest Eye is Tony Morrison's (1970) first novel, which won the Nobel Prize for Literature in 1993. The research on this novel has developed from single to diversified interpretations. To sort out its research development context and current situation is helpful to arouse more attention to the social standards of value on this novel. Until Morrison won the Nobel Prize for Literature, people begin to pay attention to her works. At first, there were few studies about her works. With the dissemination of her novels and book reviews, there has been a strong interest in her works in academic circles, and in recent years, it has become one of hot topics. The research on the novel can be divided into three stages.

In the early stage, scholars mainly introduced her works. The preliminary exploration of Tony Morrison's works was published in the Fourth Issue of Foreign Literature in 1988; scholars began to pay attention to the black democratic movement and the feminist movement. In 1993, the People's Daily gave a detailed account of Morrison and her works to Chinese readers and literary critics. In 1994, three papers about Morrison were published in the First Issue of Foreign Literature. Zhang Hong (1994) gave a presentation of the spiritual dilemma in cultural conflict on Toni Morrison's novel, interpreted The Bluest Eye, and explored Morrison's unique creative techniques.

In the second stage, the research over this novel has entered a deeper stage. Wang Shaoping (1997) discussed the structural characteristics of the novel in his article entitled "On Reversed Time and Absurd Society". Yang Jingren (1998) explored the charm of language in The Bluest Eye in his article "Reader is a part of the text as a whole”. Wang Shouren and Wu Xinyun (1999) published another article entitled "Gender, race and culture: Tony Morrison and African American literature in the 20th Century", and it represents a new stage.

In the third stage, the study of The Bluest Eye has entered a mature stage. After entering the 21st century, great breakthroughs have been made about the studies of The Bluest Eye in terms of quantity, quality, and depth, and a situation of flowers blooming has emerged. Many scholars begin to pay attention to the complexity and 
diversity of its texts. The research direction of this stage can be roughly divided into three categories: literary criticism, narrative structure, and linguistic structure.

To sum up, the research about The Bluest Eye has undergone through three stages, from introduction, continuous dissemination, to maturity. Scholars have combined western literary theory with social ethics and morality to study the novel in a multi-dimensional and deep-seated way, and expounded racial discrimination and inequality in American society at that time, appealing to the world to treat people equally and coexist peacefully.

\section{Metaphorical Concepts in the Novel}

The Bluest Eye is about the painful life of an 11-year-old black girl named Claudia in a black community in Lorraine, Ohio, in 1941. The story is originated from a girlfriend of the author's childhood, who prays to God day and night asking for a pair of blue eyes like a white girl. Because in her young eyes, if she had a white girl's blue eyes, her life would become different. Her father would not beat her mother Pauline. Her mother Pauline would no longer dislike her ugliness, neglect her, and abuse her. Her brother would not run away from home frequently. School teachers and classmates would no longer despise her and laugh at her. One day Claudia's father raped her in a drunken state. She became frantic. The contempt and ridicule of the people around her finally broke her mind and made her insane. She was completely immersed in her fictional world and firmly believed that she had a pair of beautiful blue eyes. These blue eyes did not let her see the world around her; on the contrary, she could no longer see the world accurately, and became more insignificant in the eyes of others. The Bluest Eye focuses on people's cognitive experience, value judgment, and sense of survival. The writer cannot solve the problem of the black people's distorted values in the conflict between black and white cultures, but she actually presents a social system that cannot be called justice and morality. The following four conceptual metaphors are discovered from the novel.

\section{The Four Seasons}

The first conceptual metaphor "Life is four seasons" is reflected in this novel. The source domain is four seasons, and the target domain is life. Mappings are transmitted from the source domain to the target domain. In Chinese culture, the cycle of seasons represents birth, growth, death, and regeneration. It shows that human life has similar running rules. This novel breaks the traditional narrative mode. On the contrary, the main narrative sequence is autumn, winter, spring, and summer. Through this kind of sequence, the author can highlight the symbolic topic of natural season and social life. The arrangement of seasons breaks the conventions of spring, summer, autumn, and winter. This order symbolizes that the little girl lived in an extremely chaotic and distorted social environment. Her miserable experience is as inevitable as the four seasons in nature. This reversal order also symbolizes the value orientation of white culture and lifestyle, which would surely results in mental disorder and troubles. In traditional Chinese culture, autumn is a season of harvest, which is the richest and happiest season of the year. However, the protagonist is subjected to other people's cynicism because of her ugly appearance, which makes her feel the indifference and ruthlessness of the world. The image of winter means cold and withering. The description of winter in the novel shows the vicious living environment and the cold society. For example, in the novel, a black boy scolds the protagonist as a "little nigger" and a light-skinned black girl laughs at the protagonist as a representative of beauty. She says that she is beautiful and lovely while Claudia is black and ugly. In autumn, people should have felt warm 
and comfortable, but the little girl never. Spring should be a beautiful season for all things to recover, birds to sing and flowers to throw off fragrance, being a symbol of new life and resurrection. People cheer and jump in the spring, while the spring in the novel is full of cruelty, where they cannot feel the signs of life and appreciate the value of life. Summer is a rainy season, especially in the south, there will be more than a month of plum rainy season. In the novel, the summer rainstorm has a dual symbolic meaning. First of all, rainstorms have an extremely destructive effect. Floods and water-logging often occur, affecting people's lives and cropping cultivation. People often associate the destructive effect of rainstorms with the tragic destination. The novel describes a series of tragic endings, such as the protagonist's broken family; her mental breakdown; Sam's departure from home. Later Jolly died in a civilian shelter, and her child died prematurely. She gradually became insane. These tragic experiences are all the rainstorms in her miserable life.

\section{The Bird}

The second conceptual metaphor is "Black slave is bird in cage". A bird in cage is source domain; a black slave is target domain. A bird represents freedom, but Claudia is imprisoned by the social environment. The image of a bird arises three times in this novel. The first time is when the protagonist is humiliated by a light-skinned black girl, she is like a wounded bird, and no one cares about it. She felt helpless, curling up lonely and like the folded wings of a bird when it is injured. It reveals that the little girl did not rise up to resist when being bullied by other girls of her age. Obviously, the little girl has a very low social status. The pressure can be felt from many aspects: Her teacher dislikes her and does not care for her family. The candy shopper looks down upon her and he even does not want to take money from her hand. This kind of life makes her ashamed and self-abasement. She is actually imprisoned in the social cage, and loses the right to fly, just like a captured bird. She longs for freedom, for the freedom to sing with abandoning the discrimination of the white culture and the abandonment of this cruel society. However, the image of birds stands for freedom. It should fly freely in the sky. But in this novel, birds can only put their wings away after being hurt. They cannot show their original image, let alone challenge the high altitude. Claudia is supposed to be a school girl who is innocent and romantic, and tries her best to learn knowledge. However, the protagonist Claudia loses the consciousness of independent thinking because of personality discrimination. She is no longer a character with complete personality, but also loses the capacity of flying in the sky. Claudia lives at the bottom of society and cannot get in touch with the high quality life. The influence of ethnic oppression and sexism on Claudia is beyond description. The little bird, which can use its wings to soar in the air, can only put its wings back together and loses the power and knowledge to fly in the sky. By using metaphorical means, the author emphasizes the hurt of the soul of black people in this period and, at the same time, shows that black people are influenced by the values of the white.

\section{The Doll}

The third conceptual metaphor can be represented as "Value is doll". Doll is source domain and value is target domain. Doll is a particularly important and obvious image in this novel. The doll is a special gift, and it has a high value in the eyes of adults. This value is not the numerical value of the usual price tag, but the psychological value of happiness. It seems that all the girls will take the doll as a treasure, except Claudia. Doll can stand for beauty, the embodiment of people's pursuit of aesthetic value, and the embodiment of white people's enslavement of black spirit. In a secular society, the doll is very beautiful, symbolizing the white and implying that the black people are not qualified to have one due to the ugliness of the black people. The charm 
of the doll is not at the beginning, but due to the erosion of the prevailing culture, which leads the black to abandoning their original spiritual culture, identifying with the aesthetic trend and value of the white people. Therefore, in the process of production, a standard doll is designed to have white skin and blue eyes. Black children seem to be able to change their eyes by making intimate contact and playing with blue-eyed dolls. The spiritual pursuit of black children is to have blue eyes. Claudia, the protagonist, wants to be like a white girl with big blue eyes. This novel permeates a kind of thought cognition at that time-black is a kind of ugliness; they strive to pursue white skin. With the discrimination, black people are not only enslaved by the white for a long time, but also controlled by the white in ideology and value judgement. Based on the aesthetic values presented to the white people, the black people are more obsessed with dolls with white skin and blue eyes. An obsession that makes the black more subservient to the white ideological rule is a deep expression of subjugation and spiritual distortion of vulnerable groups. The doll, which permeates the black people's thought cognition, and finally makes the black people lose themselves and their original culture, therefore going to the abyss of thought. It can be said that through the use of the image of doll, the author expresses the distorted and controlled values imposed on the black people. This metaphor also faintly implies an irony of the black people's skin and eyes because the stereotype of the doll is designed and made by the white people.

\section{The Marigold}

The fourth conceptual metaphor can be represented as "Death of hope is marigold". Marigold is source domain and death of hope is target domain. Marigold is often related to death and also presents metaphorical meaning in this novel. The novel begins by saying that in the season of fall in 1941, Claudia's marigold did not grow. That year, Claudia was raped and then she became pregnant because of his mindless father. Her life was miserable for a long time. She nearly lost the motivation to live. While the protagonist Claudia was being talked about and rejected by others. They wished that the child of Claudia would survive, so they buried the marigold under the soil, waiting for the marigold to germinate and break the earth. But the fact was that the marigold had not survived, and the sisters finally understood that all the soil was hostile to marigold. In this novel, the symbolism of marigold is ingenious and intriguing. Marigold represents longevity in China and symbolizes the purity and perfection of the Virgin Mary in the West. Their sincerity is reflected in the way they solemnly contribute their money and the sale of the remaining marigold. They consider that if the marigold could sprout, Claudia's child would be safe. However, the renewal is distorted into the adultery of her father, her virginity is ruined, the stillness of life is broken, and she lives in the abyss of darkness and pain. For marigold, the soil is bad and does not provide the nutrients for growth. Although slavery in the United States has been abolished for more than 100 years, the black people still cannot completely escape from social oppression. Through this novel, we can find that the society, including family and other aspects hold a cold attitude towards the protagonist. Even if Claudia's life suffers and she gradually goes to the abyss of despair, no one offers Claudia an effective hand. And the soil does not welcome them and has a hostile attitude towards them. The metaphorical meaning is that the black people could not get the nutrients to survive in the American land at that time. Racial discrimination leads to the distortion of the black spirit, and their soul becomes more desolate. Tens of millions of black people cannot survive in this land, just like the seed of marigold. The seed of their hope is died. It is impossible to grow marigold in such poor condition. All the black people's dreams of life are broken by this senseless fact, doomed to have no chance of success. Like Claudia, black people often talk about her and she is ignored by parents. The image of marigold metaphorically indicates that Claudia's dream of 
having a pair of beautiful blue eyes is about to die. Therefore, Claudia's biggest wish is to have big blue eyes like a white girl and live a happy life, but it is actually impossible. The seed of hope is bound to die. Due to the white discrimination, black isolation, family disregard, and self-loathing, Claudia struggles at the edge of society, and she finally falls into the endless abyss of inequality.

\section{Conclusion}

From the above analysis, we can find that conceptual metaphors in cognitive linguistics can help us better understand the concepts of four seasons, bird, doll, and marigold in The Bluest Eye. Conceptual metaphor is a mapping across from source domain to target domain. By analyzing conceptual metaphor, we can better grasp the connotations of the key concepts so that we can understand the theme of the novel better. The conceptual metaphors of the four seasons, doll, bird, and marigold emphasize the spiritual damage that black people suffer in that period. They also serve to expose the social system and values then. The novel is set against the background of the spiritual enslavement: Black Americans suffer from the "spiritual enslavement" that white Americans strive to eradicate the ancient cultural traditions of black Americans. Although the "physical slavery" to black Americans has gone forever, nevertheless, the poverty and racial discrimination of black people in the southern United States are left behind. The evil result of "spiritual slavery" is that some blacks are willing to improve their material life and accept the values of the white people in an all-round way. Real independence and equality are still on the way.

\section{References}

Barsalou, L. (1999). Perceptual symbol systems. Behavioral and Brain Sciences, 22, 577-609.

Boroditsky, L. (2000). Metaphoric structuring: Understanding time through spatial metaphors. Cognition, 75(1), 1-28.

Croft, W. (1998). Mental representations. Cognitive Linguistics, 9(2), 151-174.

Cruse, D. A. (2000). Meaning in language. Oxford: Oxford University Press.

Evans, V., \& Green, M. (2006). Cognitive linguistics: An introduction. Hillsdale, NJ: LEA and Edinburgh: Edinburgh University Press.

Fauconnier, G., \& Turner, M. (1980). Conceptual integration networks. Cognitive Science, 22(2), 133-187.

Kovecses, Z. (2002). Metaphor: A practical introduction. New York: Oxford University Press.

Lakoff, G. (1987). Women, fire, and dangerous things: What categories reveal about the mind. Chicago: University of Chicago Press.

Lakoff, G. (1993). The contemporary theory of metaphor. In A. Ortony (Ed.), Metaphor and thought (2nd ed., pp. 202-251). Cambridge: Cambridge University Press.

Lakoff, G., \& Johnson, M. (1980). Metaphors we live by. Chicago: University of Chicago Press.

Langacker, R. W. (1990). Concept, image and symbol: The cognitive basis of grammar. Berlin: Mouton dc Gruyter.

Morrison, T. (1970). The bluest eye. The United States: Vintage Books Press.

Wang, S. P. (1997). Reversed Time and Absurd Society: A Brief Comment on the Structural Characteristics of Morrison's Novel The Bluest Eye. Journal of Qiqihar Normal University (Philosophy and Social Sciences Edition).

Wang, S. R., \& Wu, X. Y. (1999). Gender, Race and Culture: Tony Monison and African American Literature in the 20 th Century. Beijing: Peking University Press.

Yang, J. R. (1998). Readers are a part of the text as a whole (Bluest Eye) and Structural Art. Foreign Literature Studies.

Zhang, H. (1994). The Presentation of the Spiritual Dilemma in Cultural Conflict: a Brief Commentary. Foreign Literature Review. 